\title{
High common childhood illnesses while the treatment-seeking behavior of mothers/caregivers' was low in rural northwest Ethiopia in 2018. A community-based cross-sectional study
}

\author{
Zemene Tigabu Kebede \\ University of Gondar \\ Kassahun Alemu Gelaye \\ University of Gondar \\ Mehari Woldemariam Merid ( $\square$ mehariho19@gmail.com ) \\ University of Gondar
}

Temesgen Yihunie Akalu

University of Gondar

Ashenafi Tazebew Amare

University of Gondar

Alemayehu Teklu Toni

University of Gondar

Gashaw Andargie Bikis

University of Gondar

Tadesse Awoke Ayele

University of Gondar

Research article

Keywords: Childhood illness, determinants, health-seeking behavior, Ethiopia

Posted Date: November 2nd, 2020

DOI: https://doi.org/10.21203/rs.2.17005/v4

License: (c) (1) This work is licensed under a Creative Commons Attribution 4.0 International License.

Read Full License 


\section{Abstract}

Background: In most developing countries, childhood illness, and deaths are among the most challenging health issues. Most of these deaths were due to preventable causes including acute respiratory infections (ARI), diarrhea, and febrile illnesses. Thus, the identification of determinants of this childhood illness would help to guide strategic planning and prioritize interventions.

Method: Community based cross-sectional study was conducted. A two-stage cluster sampling technique was used to select households and mothers/caregivers. A total of 2,158 mothers/caregivers with at least one under-five child were included. Mothers/caregivers were interviewed at their homes using a pretested and structured questionnaire. Adjusted Odds Ratio (AOR) with a 95\% Confidence Interval (Cl) for variables with P-value $<0.05$ in the multivariable model were reported to show the significance and the direction of the association.

Result: The overall prevalence of childhood illnesses was $16.5 \%$ (95\% Cl: $15.0,18.2)$. Of all, $6.5 \%$ (95\% Cl: $5.5,6.72), 7.5 \%$ (95\% Cl: $6.5,8.76)$, and $12.0 \%$ (95\% Cl: 10.66, 13.40) had diarrhea, ARI, and fever, respectively. The treatment-seeking behavior of mothers/care-givers for any of the childhood illnesses was $22.7 \%(18.72,27.42)$. The odds of childhood illness was higher among mothers' age 15-19 years (AOR=2.87-; 95\% Cl: 1.33, 6.13), employed mothers' (AOR=2.28; 95\%Cl: 1.84, 4.39), living far away from the nearest health center $(A O R=1.02 ; 95 \% \mathrm{Cl}: 1.005,1.027)$, presence of two under-five children $(A O R=1.33 ; 955 \mathrm{Cl}: 1.029,1.74)$ and three or more under-five children in the house $(\mathrm{AOR}=2.70 ; 95 \% \mathrm{Cl}: 1.12$, 6.53) than a single child. About $23 \%(95 \% \mathrm{Cl}$ : $18.7,27.4)$ of mothers/caregivers sought health care for the sick child. Mothers' occupation (AOR= 4.08 (95\% Cl: 1.35, 12.39) was the only independent predictor of treatment-seeking behavior.

Conclusion: The common childhood illness remains high while the treatment-seeking behavior of the caregivers' was low. Mothers' age, occupation, distance from the health center, and the presence of two or more under-five children in the house were independent factors of childhood illness. Being skilled mothers was significantly associated with good health-seeking behavior of mothers/caregivers. Thus, involving women in skilled/semi-skilled occupations would help in decreasing childhood illness and enhance health-seeking behaviors for their under-five children.

\section{Background}

Childhood illnesses including Acute Respiratory Infection (ARI), diarrhea, and febrile illnesses are among the most serious health issues challenging most developing countries. Globally, an estimated 5.9 million children were died before celebrating their $5^{\text {th }}$ birthday in $2015(1)$. About $75 \%$ of under-five deaths were caused by diarrhea, fever, and acute respiratory infection combined $(1,2)$ and resulted in the death of 15,000 children daily (3).

Sub-Saharan Africa still experiences remarkably high child mortality rates (4). In 2017, the region had an average under-five mortality rate of 76 deaths per 1,000 live births. About 1 in 13 children dying before his 
or her fifth birthday which is nearly 14 times higher than the average ratio of 1 in 185 in high-income countries and 20 times higher than the ratio of 1 in 263 in the region of Australia and New Zealand (2).

In Ethiopia, although significant achievements have been made in reducing childhood mortality at the national level, under-five mortality is high in the Amhara region reported as 85 deaths/1,000 live births(5). Acute respiratory infections, diarrhea, and malaria were the leading causes of death for children under five years of age $(1,2,6,7)$. Diarrhea contributes to more than one in every ten (13\%) child deaths (8). Furthermore, according to the 2016 Ethiopia Demographic and Health Survey (EDHS) report, about 12\%, $14 \%$, and $7 \%$ of under-five children had diarrhea, fever, and acute respiratory illnesses, respectivelywithin 2 weeks preceding the survey (6).

According to works of literature, age of a child, sex of a child, parental educational status, toilet facility, water source, household income, and distance from a health facility, maternal characteristics, and the number of children per household were significant factors for childhood illness (9-13).

Besides, environmental factors like indoor air pollution, type of cooking fuel, kitchen location, and exposure of children to passive smoking were significantly affecting childhood illness especially for ARI has a significant contributor (14-19).

Health-seeking behavior is a function not only of the access and availability of health facilities, and other sources of healthcare but also the motivation and ability of individuals to seek medical treatment(20). The World Health Organization (WHO) estimates that seeking prompt and appropriate care could reduce child deaths due to acute respiratory infections by $20 \%$ (21). However, significant numbers of children continue to die without appropriate treatment and ever reaching health facility or due to delays in seeking care in developing countries $(22,23)$. In Ethiopia, health care seeking behavior is poor and only a small proportion of children receive appropriate treatment. According to 2016 EDHS, only $33.3 \%$ of under-five children with a symptom of acute respiratory infection, $35 \%$ with fever, and $44 \%$ with diarrhea were taken to a health facility (24).

Although different health system initiatives and strategies have been designed and attempted to reduce child mortality in Ethiopia, childhood morbidity and mortality remain a challenge so far. Cognizant of this, the health extension workers play a significant role in improving maternal and child health through health education, providing immunization, and early screening. Ethiopia has been implementing nation-wide community health programs called health extension programs (HEP) since 2003 (25) which provide basic health and medical care close to the community, to increase access to and coverage of essential health services. Accordingly, implementation of these HEPs, play a significant role in improving maternal and child health through health education, providing immunization, and early screening (26).

Consequently, the findings of this study would be helpful to planners, policymakers, decision-makers, and as a baseline for researchers for further interventions addressing child morbidity and mortality. Therefore, this study was aimed to determine the prevalence of childhood illness and its associated factors in North West Ethiopia. 


\section{Methods}

\section{Study design, setting, and source population}

A community-based cross-sectional study was conducted from March 3-18, 2016 in the North Gondar zone, which is located in the Amhara region in the northwest part of Ethiopia (18). Amhara region, the second populated region in Ethiopia, has an estimated population of 21,134,988 according to the central statistical agency 2017 projection and of this $27 \%$ were urban residents. Amharic, the official language of the country, is the predominantly spoken language. Ethiopian orthodox Christianity church is playing a central role in the culture of Amhara people and $82.5 \%$ of the population of the Amhara region was orthodox religious followers. About $90 \%$ of their lives mainly depend on farming. Regarding women education in the region $54 \%$ were uneducated. Early marriage is a common practice in the region and about $50 \%$ of women were married below the age of 18 years. Besides, $64 \%$ of husbands rarely participate in household chores. Less than $10 \%$ of women in the region have media exposure (27). The zone has 24 districts. According to the central statistical agency (CSA) 2017, the estimated population in the North Gondar zone was $3,441,885$. Of these, 808,843 were women in the age ranges of $15-49$ years old. The estimated under-five children were 464,655 (27). As of 2016, the zone has 9 government hospitals, 126 health centers, and 563 health posts providing health care services. Mothers/caregivers with children age between one and 59 months were included in the study.

\section{Sample, data collection procedures and variables}

All mothers/caregivers in Northwest Ethiopia were the source population. Mothers/caregivers in the selected kebeles were the study population. A pilot study was done out of the study area and the sample size was determined based on the findings of the pilot study using the following assumption. $\mathrm{A} 95 \% \mathrm{Cl}$, power $(80 \%)$, percent of outcome in unexposed $(9 \%)$, odds ratio $(1.51)$, non-response of $10 \%$, and the design effect of 2 was used. Accordingly, 1012*2 plus non-response of $10 \%$ yields a total of 2226 samples. Two stages of the stratified cluster sampling technique were used. A pretested structured interviewer-administered questionnaire was used to collect the data. The questionnaire was translated to Amharic and back-translated to English to check the consistency. Mothers/caregivers were interviewed at their homes. In the case of more than one child of one and 59 months in the household, data was collected from the last child. Fifty-four data collectors and five supervisors, all of them with at least a first degree in health sciences were involved in the data collection process. Two days of training on the questionnaire, way of interviewing, and ethical issues were given before the data collection.

The occurrence of childhood illness during one and 59 months of life and health-seeking behavior of caregivers/mothers while the child was sick were the outcome variables. The independent variables were classified as socio-demographic factors including the age of mother, marital status, maternal education, maternal occupation, occupation of father, father education, religion, number of sick children, and wealth index; environmental factors including a source of water, cook in the house, types of toilet facility, and types of cooking fuel; clinical factors including birth weight, pregnancy status, place of last delivery, PNC 
attendance, home delivery practice, received health education, pre-lacteal feeding, initiation of breastfeeding, bottle feeding, and pregnancy complication.

In this study, common childhood illnesses including ARI, diarrheal diseases, and febrile illnesses were the outcome variables. The presence of childhood illness was defined as the presence of at least one of the following (cough, diarrhea, fever) within two weeks preceding the survey. ARI was defined as the presence of cough and difficulty of breathing which is reported by mothers or caregivers. Diarrhea was defined as the presence of three or more loose/watery stools per day, or blood in the stool as perceived and reported by mothers or caregivers. Fever was defined as a subjective feeling of elevated body temperature reported by mothers or caregivers. Health care-seeking behavior, the other outcome variable was defined us as mothers/caregivers' response to signs and symptoms of illnesses to reduce severity and complication after recognizing the child's illness. The independent variables include Socio-demographic characteristics of the parents: age, educational status, marital status, occupation, wealth index, and the number of children in the house; basic reproductive characteristics of the mothers and the child: place of delivery, postnatal care utilization, home delivery practice, childbirth weight, prelacteal feeding, initiation of breastfeeding, bottle feeding practice; Environmental factors: water source, toilet type, and cooking in the house.

\section{Data processing and analysis}

The data were entered and cleaned using Epi-Info version 7and analyzed using STATA version14. Data cleaning, coding, and recording were made. Descriptive statistics in the form of means for continuous variables and percentages for a categorical variable were made. Then the findings were presented by tables and texts. Variables with a p-value $\leqq 0.2$ in the bi-variable analysis were fitted in the multivariable model. Adjusted Odds Ratio (AOR) with a 95\% Confidence Interval (Cl) and p-value $<0.05$ in the multivariable model were used to declare significant association with childhood illness. The goodness of fit was checked using Hosmer and Lemeshow test with a p-value of 0.37 .

\section{Results}

\section{Socio-demographic characteristics of mothers/caregivers}

This study included 2,158 mothers/caregivers with a response rate of $96.95 \%$. The mean ( \pm SD) age of mothers/caregivers was $27.5( \pm 6.6)$ years. The median (IQR) age of the children was 3.1 (3-4.) years. About 776 (33.6\%) of mothers/caregivers were in the age group of 30-39 years old. The majority, 2,046 (94.8\%) were married, and $1413(65.5 \%)$ of respondents were uneducated, and 2,126 (98.5\%) of them were orthodox by religion, and (20.0\%) were the poorest by economic status. About 1,069 (49.5\%) of fathers were uneducated (Table 1). 
Table 1: Socio-demographic characteristics of parents at North Gondar Zone, Northwest Ethiopia, 2016 


\begin{tabular}{ll}
\hline Variables & Frequency (\%) \\
\hline Age of women & $222(10.3)$ \\
$15-19$ & $504(23.4)$ \\
$20-24$ & $526(26.7)$ \\
$25-29$ & $776(33.6)$ \\
$30-39$ & $130(6.0)$ \\
$40-49$ & \\
Marital status & $34(1.6)$ \\
Single & $2,046(94.8)$ \\
Married & $78(3.6)$ \\
Divorced, separated, and widowed & \\
Occupation of Mother & $13(0.6)$ \\
Unemployed & $55(2.6)$ \\
Unskilled/daily laborer & $13(0.6)$ \\
Semi-skilled & $2,074(96.1)$ \\
Skilled & $16(0.7)$ \\
Occupation of father & \\
Unemployed & \\
Unskilled/daily laborer & \\
Semi-skilled (Farmer\& merchant) & $28(14.4)$ \\
Skilled/professionals & \\
The educational level of Mother & \\
None & \\
Primary & \\
Secondary & \\
Higher education & \\
\hline
\end{tabular}


None

Primary

Secondary

Higher education

\section{Religion}

Orthodox

Muslim

Wealth index

Poor

Middle

Rich

Number of sick children

One

Two

Three
$1,325(61.4)$

683 (31.7)

$129(6.0)$

$21(1.0)$

$2,126(98.5)$

$32(1.5)$

$863(40.0)$

$432(20.0)$

$863(40.0)$

$279(75.4)$

$82(22.2)$

9 (2.4)

\section{Environmental factors of mothers/caregivers}

Regarding on source of drinking water, 917 (42.5\%) of mothers/caregivers used piped water. Of all the mothers/caregivers, 1,742 (80.72\%) cooked food inside the home (Table 2).

Table 2: Environmental characteristics of mothers/caregivers at North Gondar Zone, Northwest, Ethiopia, 2016 


\section{Variables $\quad$ Frequency (\%)}

\section{Water source}

Not improved $\quad 1385(64.18)$

Improved $\quad 773(35.92)$

Toilet type

Not improved $\quad 2,052(95.09)$

Improved $106(4.91)$

Cook in the house

Yes $\quad 1,742(80.7)$

No

\section{Clinical characteristics of mothers/caregivers and children}

Nearly one-third of the children, 620 (28.7\%) were low birth weight. About 1,601 (74.19\%) of the respondents had wanted pregnancy. Nearly two-thirds of the mothers/caregivers, 1,027 (64.59\%) delivered at home. About $1370,(86 \%)$ of the mothers/caregivers had no postnatal care service utilization. Only 897 (41.57\%) of the mothers/caregivers received health education by health extension workers. Of all children, 523 (32.91\%) had a history of prelacteal feeding practice. Six hundred twenty-three (28.87\%) of children had a history of bottle feeding (Table 3 ).

Table 3: Basic reproductive related characteristics of mothers/caregivers and children in North Gondar Zone, Northwest Ethiopia, 2016 


\begin{tabular}{ll}
\hline Variables & Frequency (\%) \\
\hline Birth weight & $620(28.7)$ \\
Low birth weight| & $1,475(68.4)$ \\
Normal & $63(2.9)$ \\
Large & \\
Was preterm & $1,104(96.0)$ \\
No & $46(4.0)$ \\
Yes & \\
Pregnancy wanted & $557(25.8)$ \\
No & $1,601(74.2)$ \\
Yes & $1,027(64.6)$ \\
Place of last delivery & $563(35.4)$ \\
Home & $220(13.8)$ \\
Institution & \\
PNC attendance & \\
No & \\
Yes &
\end{tabular}

Home delivery practice

No

$1,647(76.3)$

Yes

$511(23.7)$

Received health education

No

$1,261(58.4)$

Yes

897 (41.6)

Prelacteal feeding

Yes

523 (32.9)

No

1,066 (67.1)

Initiation of breastfeeding 
Within 1 hour

After 1 hour

Bottle feeding practice

Yes

No

Pregnancy complication

No

Yes
$613(28.4)$

$1,545(71.6)$

$623(28.9)$

$1,535(71.1)$

\section{Childhood illness prevalence and health-seeking behavior}

The overall prevalence of childhood illnesses among under-five children preceding within two weeks of the survey was $16.5 \%(95 \% \mathrm{Cl}: 15.03,18.17)$. The prevalence of childhood diarrhea, ARI, and fever was estimated as 6.5\% (95\% Cl: 5.5, 6.7), 7.5\% (95\% Cl: 6.5, 8.8), and, 12.0\% (95\% Cl: 10.7, 13.4), respectively. The treatment-seeking behavior of the mothers/caregivers for any of the childhood illness was $22.8 \%$ (95\% Cl: 18.7, 27.4). Of the 370 children of under five years of age who had one or more childhood illnesses, mothers/caregivers sought care at health facilities for only 63 (45\%) ofdiarrhea, 97 (37.6\%), of fever, and 17 (10.3\%) ARI cases (Table 4).

Table 4: Clinical characteristics among sick children in North Gondar Zone, Northwest Ethiopia, 2016 


\begin{tabular}{ll}
\hline Variable & Frequency (\%) \\
\hline Cough/difficulty of breathing & $202(55.0)$ \\
No & $165(45.0)$ \\
Yes & \\
Sought medical treatment for cough & \\
Yes & $17(10.3)$ \\
No & $148(89.7)$ \\
Take-home treatment & $113(68.5)$ \\
No & $52(31.5)$ \\
Yes & \\
Outcome of child & $123(74.6)$ \\
Improved & $23(13.9)$ \\
Deteriorated & $19(11.5)$ \\
Other & $109(29.7)$ \\
Child had diarrhea & $258(70.3)$ \\
No & \\
Yes & $224(61.5)$ \\
Had fever & $140(38.5)$ \\
No & \\
Yes & \\
childhood illness & \\
No & \\
\hline
\end{tabular}




\section{Factors affecting childhood illnesses}

In the bivariate analysis age of mother, bottle feeding, distance in kilometer from the health center, occupation of mother, wealth index, source of drinking water, cook in the household, and the number of children in the household were significant determinates of childhood illness. However, in the multivariable analysis, the age of mother, distance in kilometer from the nearest health center, occupation of mother, and the number of under-five children in the house were significant factors of childhood illness. The odds of childhood illness among caregivers of age 15-19 years was 2.87 times higher compared to caregivers of age 40 years and above years. In contrast, for a unit increases in 1-kilometer distance from the health center, the odds of childhood illness were increased by $2 \%$. Moreover, the odds of developing childhood illness among semiskilled/skilled mothers were 2.28 times that of unskilled mothers. Mothers having 2 and 3 or more children increase the odds of developing childhood illness by 1.33 and 2.7 times, respectively compared with mothers with single children (Table 5).

Table 5: Factors affecting childhood illnesses among mothers/caregivers in North Gondar Zone, Northwest Ethiopia, $2018(\mathrm{~N}=2,158)$ 
Variables

childhood illness

COR ( 95\% CI ) AOR (95\% CI)

Yes (\%) No (\%)

Age of mother

$15-19$

$31(14.0)$

$190(86.0)$

$1.63(0.78,3.38)$

$2.87(1.33,6.13)$

20-24

$88(17.5)$

416(82.5)

$1.92(0.99,3.73)$

$1.81(0.92,3.59)$

$25-29$

$99(19.2)$

$417(80.8)$

$1.92(0.99,3.72)$

$1.82(0.93,3.57)$

30-39

128(17.6)

598(82.4)

$1.99(1.04,3.81)$

$1.86(0.96,3.61)$

$>40$

$11(8.4)$

$120(91.6)$

1

1

Occupation of mother

Unskilled

Semi-skilled\& skilled

$342(95.79)$

$15(4.21)$

1

1

$1,750(97.17) \quad 51(2.83) \quad 1.5(0.8,2.7)$

$2.28(1.8,4.4)$

Wealth index

Poor

149(17.27)

$714(82.73)$

$1.2(1.0,1.6)$

$1.05(0.78,1.41)$

Middle

$84(19.44)$

$348(80.56)$

$1.4(1.1,12.0)$

$1.22(0.88,1.7)$

Rich

124(14.37)

$739(85.63)$

1

\section{Source of drinking water}

Not improved

Improved

$\begin{array}{lll}210(15.2) & 1,175(84.8) \\ 106(12.7) & 727(87.3)\end{array}$

$0.8(0.6,1.02)$

$0.81(0.62,1.01)$

\section{Cook in the house}

No 


\section{Number of children}

One child

Two child

Three or more

Bottle feeding

Yes

No

Distance from the HC
$191(17.1)$

117(19.9)

8(33.3)

66(11.1)

$250(16.3)$

$1,29(83.7)$

$1.71(1.3,2.3)$

$1.02(1.01,1.03) \quad 1.02(1.01,1.03)$

*AOR: Adjusted Odds Ratio, CI: Confidence Interval, COR: Crude Odds Ratio, and HC: Health center

\section{Factors affecting the health-seeking behavior of mothers/care-givers}

In the bivariate analysis age of mother, mother occupation, father education, wealth index, distance from the health center, number of under-five children in the household, and place of delivery were statistically significant at $p$-value less than 0.2 . However, in the multivariable analysis occupational status of mothers was associated with the treatment-seeking behavior of mothers/caregivers (Table 6).

Table 6: Factors affecting the health seeking behavior of mothers in North Gondar Zone, Northwest Ethiopia, $2018(\mathrm{~N}=360)$ 
Variables

mother

15-19

20-24

25-29

$>30$

Mother occupation

Unskilled

Semi-skilled and skilled

74

8

271

1

1

behavior

Yes No

Age of mother

6

26

$0.81(0.31,2.15)$

22

67

23

76

$1.06(0.58,1.97)$

31

109

1

1

$7 \quad 4.08$

Semi-skilled and skilled

$0.88(0.32,2.44)$

$1.15(0.62,2.16) \quad 1.07(0.54,2.10) \backslash$

$1.03(0.56,192)$

$4.08(1.35,12.39)$

$(1.46,11.91)$

Distance from the health center

$$
0.98(0.95,1.01) \quad 0.96(0.57,1.63)
$$

Wealth index

Poor

36

114

$0.93(0.54,1.61)$

$0.79(0.43,1.43)$

Middle

14

70

$0.58(0.29,1.18)$

$0.60(0.29,1.25)$

Rich

32

94

1 1

Number of under-five children in the house

One

1

1

Two or more 
Father education

Uneducated

Primary

Secondary and above

Place of delivery

Home

Institution
53

20

9

127

38
171

85

22

$0.76(0.43,1.35)$

$1.32(0.57,3.04)$
1

$0.69(0.37,1.28)$

$1.02(0.41,2.57)$

AOR: Adjusted Odds Ratio, CI: Confidence Interval, COR: Crude Odds Ratio, and HC: Health center

The odds of having treatment-seeking behavior among semi-skilled/skilled mothers/care-givers were four $(\mathrm{AOR}=4.08$ (95\% Cl: $1.35,12.39)$ times higher compared to unskilled mothers/care-givers.

\section{Discussion}

In our study, the overall prevalence of childhood illnesses among under-five children preceding two weeks of the survey was $16.5 \%(95 \% \mathrm{Cl}: 15.0,18.2)$. Of the illnesses, $6.5 \%(95 \% \mathrm{Cl}: 5.5,6.7)$ was accounted for diarrhea, $7.5 \%$ (95\% Cl: $6.5,8.8)$ was for ARI, and $12.0 \%$ (95\% Cl: $10.7,13.4)$ was for fever. Compared to the national figure (EDHS 2016), the finding of this study noted, a higher prevalence of diarrhea and fever which was $\mathrm{h} 12 \%$ for diarrhea and $14 \%$ for fever. However, the two weeks prevalence of ARI in this study was comparable with the national figure (7.5\%) (24).

A Systematic review and meta-analysis conducted in Ethiopia noted a higher prevalence of childhood illness compared to the current finding (28). The systematic review included primary studies done in regions with a high burden of childhood morbidities including Afar, Somali, and rural Dire Dawa where health care access is limited. This might have been attributed to the higher pooled prevalence of childhood illnesses.

Similarly, the result of this study noted a lower prevalence of childhood illness compared to some studies conducted elsewhere $(9,11,13,16,29)$. There could be several explanations for the differences in the prevalence of the illnesses with the current finding and across works of literature. For instance, the study in Tanzania included three remote districts located 200-400 kilometers from the capital of the country. All three districts were predominantly rural and impoverished with poor transportation, infrastructure, and subsistence agriculture is driven economy thereby limited availability and poor access to health care 
services. Likewise, the study done in Kenya was from two slum areas where the majority of the residents seek health care outside of health institutions. They mainly visited local drug shops, faith-based institutions, and to some extent private clinics. And pieces of evidence showed a strong relationship between the increased occurrence of childhood morbidity and health-seeking behavior outside of health institutions (30-32). Besides, the study in Nigeria included a small sample of caregivers (450) in a single setting of a local government area, Lagos State, and included all children aged 0-5 years. This might overestimate the proportion of illnesses compared to our findings.

Furthermore, our finding noted the lower prevalence of childhood illnesses, particularly childhood diarrhea, compared to different studies conducted in different regions and districts in Ethiopia $(7,25,26$, 33-42). Sample size, year of study, and study setting were some of the factors for the differences in the prevalence of childhood illnesses across our study and the aforementioned literature. For example, one of the studies (43) was conducted in three small kebeles and used only 405 caregivers in the study. Similarly the study from the Jeldu district of the Oromia region, Ethiopia was done on a relatively small sample size (422) caregivers might underestimate the magnitude of childhood illness compared to our findings.

Overall, about $22.7 \%$ [95\% Cl: $18.72,27.42]$ of mothers/caregivers sought health care for the sick child. Treatment seeking behavior from health care facilities in this study was consistent for diarrhea and fever but lower for ARI compared to the EDHS report. The lower care-seeking behavior for ARI could be the mothers' perception of mild illness of cough as the common cold (44). This study has also noted that the treatment-seeking behavior of the mothers/caregivers was lower compared to similar studies done elsewhere $(29,31,45-47)$. There could be several explanations for the differences in treatment-seeking behavior of the mothers/caregivers for common childhood illness. Some of the possible reasons that affect common childhood illnesses are visiting traditional healer's first, financial constraint, the perception that illness was not serious, and the expectations that illness would recover soon $(29,30,48)$. However, the treatment-seeking behavior of the mothers/caregivers in our study was higher compared to similar studies conducted in other parts of the country elsewhere $(7,38,49,50)$. The possible reason is that some of the above studies were conducted in relatively urban areas where residents had better socioeconomic status, and good awareness and attitude to seek modern care for their children $(50,51)$.

Different categories of factors including maternal socio-demographic characteristics, child-related, and household environmental factors were significantly associated with childhood illness. Accordingly, maternal age, number of children in the household, mother occupation, and distance from the nearest health center were the independent determinants of childhood illness.

In this study, it was noted that a child who lived in a family with three and/or more under-five children was more likely to have childhood illness than a household with only one child. This finding was supported by similar studies conducted elsewhere $(39,52-54)$. This could be possibly explained in that when the number of children in the household increases, it is expected that children could be more vulnerable to contamination because the quality of care and attention from parents decreases as mothers become 
incapable of caring for children. Furthermore, children who get the disease may easily transmit to others who live in the same area.

Moreover, the odds of developing childhood illness among children of semi-skilled/skilled mother occupational status were 2.3 times compared with unskilled mothers. This finding was in agreement with previous studies $(40,54-56)$. The possible reason is that mothers with a skilled occupation usually work outside of their home which they might not have adequate time to care for their children as a motherhood role. As a result, children of those mothers might not receive the quality care from the servants/ caregiver than were supposed to get from their mothers. However, this finding was in contrast with a study done in Ethiopia to determine the risks of under-five diarrheal and fever morbidity in which children of mothers/caregivers with working status were more at risk of getting childhood illnesses (59). This can be justified in that maternal occupation and income are factors that provide information about the level of autonomy of the woman that could empower herself to take care of her child $(57,58)$.

The occurrence of childhood illness was inversely associated with distance to a health facility. Children who lived near health facilities received more care than those who lived far from a health facility $(60,61)$. This finding was also consistent with other data from previous reports $(9,33,62)$. This can be explained by the fact that children living in families located far from health facilities are denied the availability and get access to the preventive and treatment services for common health problems which in turn led to the occurrence of increased childhood morbidity.

Different scholars have indicated that several factors were associated with the health-seeking behavior of mothers/caretakers for common childhood illnesses including maternal education level, family income, and perception of illnesses, residence, knowledge, and distance from health institutions. However, in the current study, mothers' occupation was the only independent predictor of treatment-seeking behavior. Thus, the odds of having treatment-seeking behavior among semi-skilled/skilled mothers/care-givers were four ( $\mathrm{AOR}=4.08(95 \% \mathrm{Cl}: 1.35,12.39)$ times higher compared to unskilled mothers/care-givers. This finding was supported by previous studies $(63,64)$. This could be explained in that employed mothers usually have higher income and perhaps would be better educated and have enough resources for seeking treatment to their sick children in which they are more likely to visit health facilities for illnesses before it gets worse.

Finally, this study was not without its limitations. Since data collections were based on mothers/caregivers' responses that there could be room for recall bias and social desirability bias.

Furthermore, morbidity data were subjective since it was based on self-reported treatment-seeking patterns without validation by medical personnel. It is also difficult to establish a cause-effect relationship because of the cross-sectional nature of the data. Moreover, contextual factors like cultural practices and health-seeking for traditional medicine, and some children's data were not included. Despite these limitations, the findings of the study will be generalized to rural northwest Ethiopia and other similar settings. 


\section{Conclusion}

In this study, a common childhood illness remains high while the treatment-seeking behavior of mothers/caregivers' was so low in the study setting. Mothers' age and occupation, distance from the nearest health center, and the presence of three or more under-five children in the house were independent determinants of childhood illness. Being a skilled/semi-skilled mothers was significantly associated with good health-seeking behavior of mothers/caregivers. Thus, involving women in skilled/semi-skilled occupations would help in decreasing childhood illnesses and enhance health-seeking behaviors for their under-five children. Besides, providing access to health care facilities in their nearby area would be highly essential in reducing childhood illness.

\section{List Of Abbreviations}

The following are some of the key abbreviations used in this study. ARI-acute respiratory infections, PNCpostnatal care, EDHS-Ethiopian demographic and health survey, U5-under five, WHO-world health Organization, AOR-adjusted odds ratio, Cl-confidence interval, SD-standard deviation, EMDHS -Ethiopia Mini Demographic and Health Survey

\section{Declarations}

\section{Ethics approval and consent to participate}

Ethical approval was obtained from the University of Gondar Institutional Review Committee (IRC). A permission letter was obtained from all local administrators and health managers. Written informed consent was obtained from mothers/caregivers. For mothers/caregivers less of age than 18 years, assent was obtained. All study participants were informed that participation was voluntary. The potential benefits, harms, confidentiality, and the possibility of withdrawing from the interview at any time of the interview and after were also informed.

\section{Consent for publication}

Not applicable

\section{Availability of data and material}

The data used to support the findings of this study are available from the corresponding author upon reasonable request.

\section{Competing interests}

The authors declare they have no competing interests.

\section{Funding}


The study has no funding source.

\section{Author contributions}

AT, MW/M, ATT, and GA developed and reviewed the proposal. ZT, KA, TA, TY analyzed and interpreted the patient data regarding childhood illnesses. KA, M/WM, and TY were the major contributors in writing the manuscript. All the authors have participated in preparing and approving the manuscript.

\section{Acknowledgment}

The authors acknowledge all mothers/caregivers of children for their cooperation and willingness. We would also like to thank data collectors for their great collaboration and tolerance for this research work.

\section{References}

1. World Health Organization. Monitoring health for the SDGs sustainable development goals.: World Health Organization; 2016.

2. World Health Organization. Levels and trends in child mortality. 2018.

3. Hug L, Sharrow D, You D. Levels \& trends in child mortality: report 2017. Estimates developed by the UN Inter-agency Group for Child Mortality Estimation. 2017.

4. Wang H, Liddell CA, Coates MM, Mooney MD, Levitz CE, Schumacher AE, et al. Global, regional, and national levels of neonatal, infant, and under-5 mortality during 1990-2013: a systematic analysis for the Global Burden of Disease Study 2013. The Lancet. 2014;384(9947):957-79.

5. World Health Organization. Ethiopia Mini Demographic and Health Survey 2019.

6. Gaither Road, Rockville. Ethiopia Demographic and Health Survey 2016. 2016 Jun. Report No.: 02640325 (Print)

7. Kolola T, Gezahegn T, Addisie M. Health care seeking behavior for common childhood illnesses in jeldu district, oromia regional state, Ethiopia. PloS one. 2016;11(10):e0164534.

8. Organization WH. Global status report on noncommunicable diseases 2014. World Health Organization, 2014.

9. Kante AM, Gutierrez HR, Larsen AM, Jackson EF, Helleringer S, Exavery A, et al. Childhood Illness Prevalence and Health Seeking Behavior Patterns in Rural Tanzania. BMC public health. 2015;15:951.

10. Gebretsadik S, Gabreyohannes E. Determinants of under-five mortality in high mortality regions of Ethiopia: an analysis of the 2011 Ethiopia demographic and health survey data. International Journal of Population Research. 2016;2016.

11. Thiam S, Diene AN, Fuhrimann S, Winkler MS, Sy I, Ndione JA, et al. Prevalence of diarrhoea and risk factors among children under five years old in Mbour, Senegal: a cross-sectional study. Infectious diseases of poverty. 2017;6(1):109. 
12. Kotloff KL. The burden and etiology of diarrheal illness in developing countries. Pediatric Clinics. 2017;64(4):799-814.

13. Kamal MM, Hasan MM, Davey R. Determinants of childhood morbidity in Bangladesh: evidence from the demographic and health survey 2011. BMJ open. 2015;5(10):e007538.

14. Kanté AM, Gutierrez HR, Larsen AM, Jackson EF, Helleringer S, Exavery A, et al. Childhood illness prevalence and health seeking behavior patterns in rural Tanzania. BMC public health. 2015;15(1):951.

15. Fenn B, Morris SS, Black RE. Comorbidity in childhood in northern Ghana: magnitude, associated factors, and impact on mortality. International journal of epidemiology. 2005;34(2):368-75.

16. Taffa N, Chepngeno G. Determinants of health care seeking for childhood illnesses in Nairobi slums. Tropical medicine \& international health : TM \& IH. 2005;10(3):240-5.

17. Uwemedimo OT, Lewis TP, Essien EA, Chan GJ, Nsona H, Kruk ME, et al. Distribution and determinants of pneumonia diagnosis using Integrated Management of Childhood IIIness guidelines: a nationally representative study in Malawi. 2018;3(2):e000506.

18. Sonego M, Pellegrin MC, Becker G, Lazzerini M. Risk factors for mortality from acute lower respiratory infections (ALRI) in children under five years of age in low and middle-income countries: a systematic review and meta-analysis of observational studies. PloS one. 2015;10(1):e0116380.

19. Shibata T, Wilson J, Watson L, LeDuc A, Meng C, La Ane R, et al. Childhood acute respiratory infections and household environment in an eastern Indonesian urban setting. International journal of environmental research and public health. 2014;11(12):12190-203.

20. Teerawichitchainan B, Phillips J. Ethnic Differentials in Parental Health Seeking for Child Illness in Vietnam. Poverty. Gender and Youth, Population Council, USA. 2007;3.

21. World Health Organization. Technical bases for the WHO recommendations on the management of pneumonia in children at first-level health facilities. Geneva: World Health Organization, 1991.

22. Geldsetzer P, Williams TC, Kirolos A, Mitchell S, Ratcliffe LA, Kohli-Lynch MK, et al. The recognition of and care seeking behaviour for childhood illness in developing countries: a systematic review. PloS one. 2014;9(4):e93427.

23. UNICEF. Progress for children: achieving the MDGs with equity: Unicef; 2010.

24. World Health Organization. Ethiopia Demographic and Health Survey. 2016.

25. Regassa G, Birke W, Deboch B, Belachew T. Environmental determinants of diarrhea among underfive children in Nekemte town, western Ethiopia. Ethiopian Journal of Health Sciences. 2008;18(2).

26. Mohammed Al, Zungu L. Environmental health factors associated with diarrhoeal diseases among under-five children in the Sebeta town of Ethiopia. Southern African journal of infectious diseases. 2016;31(4):122-9.

27. Source for total regional population and urban/rural populations: Federal Democratic Republic of Ethiopia Central Statistical Agency Population Projection of Ethiopia for All Regions at Woreda Level from 2014-2017. . 2013. 
28. al. AAe. Prevalence and determinants of diarrhea among under-five children in Ethiopia: A systematic review and meta-analysis.

29. Adegboyega AA, Onayade AA, Salawu O. Care-seeking behaviour of caregivers for common childhood illnesses in Lagos Island Local Government Area, Nigeria. Nigerian journal of medicine : journal of the National Association of Resident Doctors of Nigeria. 2005;14(1):65-71.

30. Umuhoza C, Karambizi AC, Tuyisenge L, Cartledge P. Caregiver delay in seeking healthcare during the acute phase of pediatric illness, Kigali, Rwanda. The Pan African medical journal. 2018;30:160.

31. Wilson SE, Ouedraogo CT, Prince L, Ouedraogo A, Hess SY, Rouamba N, et al. Caregiver recognition of childhood diarrhea, care seeking behaviors and home treatment practices in rural Burkina Faso: a cross-sectional survey. PloS one. 2012;7(3):e33273.

32. Ekpo O. Careseeking for childhood diarrhoea at the primary level of care in communities in Cross River State, Nigeria. Journal of epidemiology and global health. 2016;6(4):303-13.

33. Getu D, Gedefaw M, Abebe N. Childhood diarrheal diseases and associated factors in the rural community of Dejen district, Northwest Ethiopia. American Scientific Research Journal for Engineering, Technology, and Sciences (ASRJETS). 2014;5(1):1-13.

34. Ayele A, Awoke W, Tarekegn M. Crossectional survey; assessment of diarrheal disease prevalence and the associated factors among children under five in Enemay district, northwest Ethiopia. Global Journal of Medical Research. 2014.

35. Bizuneh H, Getnet F, Meressa B, Tegene Y, Worku G. Factors associated with diarrheal morbidity among under-five children in Jigjiga town, Somali Regional State, eastern Ethiopia: a cross-sectional study. BMC pediatrics. 2017;17(1):182.

36. Gedamu G, Kumie A, Haftu D. Magnitude and associated factors of diarrhea among under five children in Farta wereda, North West Ethiopia. Quality in Primary Care. 2017;25(4):199-207.

37. Mohammed S, Tilahun M, Tamiru D. Morbidity and associated factors of diarrheal diseases among under five children in Arba-Minch district, Southern Ethiopia, 2012. Sci J Public Health. 2013;1(2):102-6.

38. Awoke W. Prevalence of childhood illness and mothers'/caregivers' care seeking behavior in Bahir Dar, Ethiopia: A descriptive community based cross sectional study. Open Journal of Preventive Medicine. 2013;3(02):155.

39. Mengistie B, Berhane $Y$, Worku A. Prevalence of diarrhea and associated risk factors among children under-five years of age in Eastern Ethiopia: A cross-sectional study. Open Journal of Preventive Medicine. 2013;3(07):446.

40. Alambo KA. The prevalence of diarrheal disease in under five children and associated risk factors in Wolitta Soddo Town, Southern, Ethiopia. ABC Research Alert. 2015;3(2).

41. Hashi A, Kumie A, Gasana J. Prevalence of diarrhoea and associated factors among under-five children in Jigjiga District, Somali Region, Eastern Ethiopia. Open J Prev Med. 2016;6(10):233-46.

42. Simieneh MM, Mengistu MY, Gelagay AA, Gebeyehu MT. Mothers' health care seeking behavior and associated factors for common childhood illnesses, Northwest Ethiopia: community based cross- 
sectional study. BMC health services research. 2019;19(1):59.

43. Awoke W. Prevalence of childhood illness and mothers'/caregivers' care seeking behavior in Bahir Dar, Ethiopia: A descriptive community based cross sectional study. 2013.

44. Gelaw YA, Biks GA, Alene KA. Effect of residence on mothers' health care seeking behavior for common childhood illness in Northwest Ethiopia: a community based comparative cross-sectional study. BMC research notes. 2014;7:705.

45. Omore R, O'Reilly CE, Williamson J, Moke F, Were V, Farag TH, et al. Health care-seeking behavior during childhood diarrheal illness: results of health care utilization and attitudes surveys of caretakers in western Kenya, 2007-2010. The American journal of tropical medicine and hygiene. 2013;89(1 Suppl):29-40.

46. Das SK, Nasrin D, Ahmed S, Wu Y, Ferdous F, Farzana FD, et al. Health care-seeking behavior for childhood diarrhea in Mirzapur, rural Bangladesh. The American journal of tropical medicine and hygiene. 2013;89(1 Suppl):62-8.

47. Villarreal I, Turner R, Jo H, Park J, Gemmen E, Pircon JY, et al. Healthcare-seeking behaviour of primary caregivers for acute otitis media in children aged 6 months to $<30$ months in Panama: results of a cross-sectional survey. BMC Pediatr. 2017;17(1):3.

48. Mitiku I, Assefa A. Caregivers' perception of malaria and treatment-seeking behaviour for under five children in Mandura District, West Ethiopia: a cross-sectional study. Malaria journal. 2017;16(1):144.

49. Abegaz NT, Berhe H, Gebretekle GB. Mothers/caregivers healthcare seeking behavior towards childhood illness in selected health centers in Addis Ababa, Ethiopia: a facility-based cross-sectional study. 2019;19(1):220.

50. Simieneh MM, Mengistu MY, Gelagay AA, Gebeyehu MT. Mothers' health care seeking behavior and associated factors for common childhood illnesses, Northwest Ethiopia: community based crosssectional study. BMC health services research. 2019;19(1):59.

51. Alene M, Yismaw L, Berelie $Y$, Kassie B. Health care utilization for common childhood illnesses in rural parts of Ethiopia: evidence from the 2016 Ethiopian demographic and health survey. BMC public health. 2019;19(1):57.

52. Mekasha A, Tesfahun A. Determinants of diarrhoeal diseases: a community based study in urban south western Ethiopia. East African medical journal. 2003;80(2):77-82.

53. Tamiso A, Yitayal M, Awoke A. Prevalence and determinants of childhood diarrhoea among graduated households, in rural area of Shebedino district, Southern Ethiopia, 2013. Science. 2014;2(3):243-51.

54. Woldu W, Bitew BD, Gizaw Z. Socioeconomic factors associated with diarrheal diseases among under-five children of the nomadic population in northeast Ethiopia. Tropical medicine and health. 2016;44(1):40.

55. Zeleke AT, Alemu ZA. Determinants of under-five childhood diarrhea in Kotebe Health Center, Yeka Sub City, Addis Ababa, Ethiopia: a case control study. Global Journal of Medical Research. 2014. 
56. Bado AR, Susuman AS, Nebie El. Trends and risk factors for childhood diarrhea in sub-Saharan countries (1990-2013): assessing the neighborhood inequalities. Global health action. 2016;9:30166.

57. Khatab K, Adegboye O, Mohammed TI. Social and Demographic Factors Associated with Morbidities in Young Children in Egypt: A Bayesian Geo-Additive Semi-Parametric Multinomial Model. PloS one. 2016;11(7):e0159173.

58. Mulugeta T. Socio-economic, environmental, and behavioural factors associated with the occurrence of diarrhoeal disease among under-five children, Meskanena Mareko Woreda, southern Ethiopia. Addis Ababa: Addis Ababa University, Ethiopia. 2003.

59. Takele K, Zewotir T, Ndanguza D. Risk factors of morbidity among children under age five in Ethiopia. BMC public health. 2019;19(1):942.

60. Deressa W, Ali A, Berhane Y. Household and socioeconomic factors associated with childhood febrile illnesses and treatment seeking behaviour in an area of epidemic malaria in rural Ethiopia. Transactions of the Royal Society of Tropical Medicine and Hygiene. 2007;101(9):939-47.

61. Akinyemi JO, Banda P, De Wet N, Akosile AE, Odimegwu CO. Household relationships and healthcare seeking behaviour for common childhood illnesses in sub-Saharan Africa: a cross-national mixed effects analysis. BMC health services research. 2019;19(1):308.

62. Bitew BD, Woldu W, Gizaw Z. Childhood diarrheal morbidity and sanitation predictors in a nomadic community. Italian journal of pediatrics. 2017;43(1):91.

63. Lee HY, Van Huy N, Choi S. Determinants of early childhood morbidity and proper treatment responses in Vietnam: results from the Multiple Indicator Cluster Surveys, 2000-2011. Global health action. 2016;9:29304.

64. Villarreal I, Turner R, Jo H, Park J, Gemmen E, Pirçon J-Y, et al. Healthcare-seeking behaviour of primary caregivers for acute otitis media in children aged 6 months to 30 months in Panama: results of a cross-sectional survey. BMC pediatrics. 2017;17(1):3.

\section{Supplementary Files}

This is a list of supplementary files associated with this preprint. Click to download.

- Stobechecklist.doc 